\title{
Dehulling effectiveness of high-oleic and linoleic sunflower oilseeds using air-jet impact dehuller: a comparative study
}

\author{
Ranko S. ROMANIĆ ${ }^{1 *}$ (D), Tanja Z. LUŽAIĆ ${ }^{1}$
}

\begin{abstract}
Sunflower seeds and kernels are very common in the preparation of protein meals. Dehulling sunflower seeds for meal preparation and direct consumption is a very important operation. High-oleic sunflower contains the most oleic fatty acids in the oil which significantly improves the oxidative stability of the meal with this sunflower compared to meals with standard linoleic sunflower seed. In this work, a air-jet impact dehuller was used to determine, optimize and compare the effectiveness of dehulling of two types of sunflower: high-oleic (HOSS) and linoleic sunflower seed (LSS). A two-factorial experimental design $\left(3^{2}\right)$ was used to estimate the effect of seed moisture and applied air pressure on the efficiency (E criterion) and quality of dehulling (K1 and K2 criteria). Samples with a moisture content of 6,8 and $10 \%$ were dehulled at an air pressure of 400, 600 and $800 \mathrm{kPa}$. The most efficient dehulling of HOSS, was achieved at a dehulling pressure in the range of 600-800 kPa and moisture content of $6.0 \%$. As for the LSS sample, the highest efficiency of LSS and the highest K2 criterion were obtained at the dehulling pressure of $800 \mathrm{kPa}$, and moisture content of $7.3 \%$.
\end{abstract}

Keywords: high-oleic sunflower seed; hull; dehulling; dehulling effectiveness.

Practical Application: Dehulling sunflower seeds with different seed moisture and dehulling pressure.

\section{Introduction}

Apart from the objectives to create sunflower hybrids with genetic potentials for the high yield of seed and high content of seed oil, the constant efforts of sunflower breeders have also been directed towards improving the quality of the obtained hybrides. Namely, the aim is to increase the nutritional value of the oil and its shelf life, and these characteristics are mainly determined by the composition of the fatty acids involved and contents of minor oil products such as tocopherols, sterols, carrotenoids, etc. (Przybylski \& Michael Eskin, 2006; Miklič et al., 2008; Wittkop et al., 2009).

Among the seeds of standard sunflowers of linoleic type, a dominant fatty acid is linoleic acid (about 65\%). However, of special importance is the sunflower of oleic type, in which, according to the adopted criteria, the content of oleic acid has to be higher than $80 \%$ (Miklič et al., 2008; Raß et al., 2008; Garcés et al., 2009). Regarding the total world production, the standard linoleic hybrids are still dominant. However, high-oleic and/or medium-oleic sunflower types are predominant in France, USA, and Spain, and their production in Hungary, Ukraine, Romania, and Argentina is significantly increasing (Dozet \& Vuković, 2007). The production of sunflower hybrids with high content of oleic acid in Serbia is among the first in Europe, and the most popular is the hybrid Olivko (Škorić et al., 1994).

Nowadays, in Serbia and many European countries, sunflower is a dominant raw material for the production of edible oils. Sunflower oil is mainly manufactured and sold as refined, and in recent years as unrefined edible, i.e. cold-pressed, oil (Dimić, 2005; Ra $\beta$ et al., 2008).
The kernels of the sunflower seeds with enhanced content of protein are widely used in the production of various bakery and confectionary products and as additives for enriching traditional meals, or as nibbles - confectionary sunflower (Sosulski, 1979). The kernel of the confectionary sunflower hybrid Cepko has a very high nutrititional value (Dimić et al., 2006). Besides the use in bakery products, sunflower kernel is added to cookies, crackers, biscuits, and snack products (Bajaj et al., 1991; Gupta et al., 2007; Pajin et al., 2011). One way to expand the uses of sunflower seeds and increase the demand for their seeds is to develop new value-added products, such as superior-quality sunflower butter, which has been commercially produced in the USA since 1980 (Lima \& Guraya, 2005).

The hull of the sunflower seeds is mainly composed of cellulosic and hemicellulosic matter, and it contains very small amounts of lipids. During the preparation of the seeds for further processing it is necessary to remove, partly or completely, the hulls, which leads to the improvement of the quality of the obtained product (refined or unrefined oils, kernels and kernel products, cakes, etc.) (Dimić, 2005; Grompone, 2020). Sunflower seeds of high-oil hybrids contain $75-80 \%$ of the kernel and $20-25 \%$ of the hull (Dimić, 2005), whereas the hull share in confectionary hybrids amounts even to $50 \%$, and its thickness is up to 0.50 $\mathrm{mm}$ (Vasić, 2006). With the high-oil hybrids of linoleic and especially of high-oleic type, the hull is thin $(0.10-0.40 \mathrm{~mm})$ and it adheres tightly to the kernel, so that the seed dehulling is hindered. The hull is removed most often mechanically on special dehullers, and the operation consists of three phases: 
breaking the hull, kernel release, and separation of the hull from the kernel. The dehullers work on different principles such as rotation (mills, cylinders, centrifuges), pneumatic impact, and the like (Dimić, 2005; Sharma et al., 2009).

Apart from the size and shape of the seed, the hull characteristics (thickness and strength), as well as its resistance to breaking, the moisture content is one of the most relevant parameters for an effective dehulling (Dimić, 2005; Figueiredo et al., 2011; Grompone, 2020). Figueiredo et al. (2011) examined the physical characteristics of the three sunflower hybrid seeds with different structural characteristics (striped-hull oilseed, black-hull oilseed and non-oilseed) and with different moisture content and concluded that seeds with smaller dimensions and higher hull content have higher dehulling effectiveness. Munder et al. (2017) examined the physical characteristics of high oleic sunflower seeds. These seeds have a thinner hull and whole seed is thinner than standard sunflower seed.

In spite of the fact that the process of dehulling of sunflower seeds is of crucial importance for the production of high-quality raw oil, and especially of unrefined edible oil, this issue has been insufficiently studied. Hence, the objective of this work was to determine, optimize and compare the effectiveness of the dehulling of two types of sunflower seeds (high-oleic sunflower seed, HOSS, and linoleic type sunflower seed, LSS). To assess the effectiveness of the process, in addition to the previously used criteria of efficiency and quality, we introduced a new quality criterion related to the content of the desirable fraction of whole kernels and large broken kernels.

\section{Materials and methods}

\subsection{Material}

The effectiveness of dehulling of the HOSS (Olivko hybrid) and LSS samples was studied using a air-jet impact dehuller (Hydromechaniques et Frottement, „Tech Machine”, France). The sunflower was grown at two locations in the Vojvodina Province (northern Serbia), Europe, mutually separated by about $5 \mathrm{~km}$. The sample of HOSS was grown in the surroundings of the town Srbobran (geographical coordinates: $45^{\circ} 33^{\prime} 14^{\prime \prime}$ North and $19^{\circ} 48^{\prime} 10^{\prime \prime}$ East) and the LSS near the town Vrbas (geographical coordinates: $45^{\circ} 34^{\prime} 17^{\prime \prime}$ North and $19^{\circ} 38^{\prime} 27^{\prime \prime}$ East), during the period of April to September of the same year of cultivation. Immediately after harvesting, the seeds were cleaned and dried below the critical (equlibrium) moisture content (4.5-5.0\%). To the moment of the preparation for dehulling, the seeds were stored in polyethylene bags at room temperature $\left(22 \pm 2{ }^{\circ} \mathrm{C}\right)$.

\subsection{Methodology}

Mass of 1000 seeds and bulk density were determined according to Karlović \& Andrić (1996). The seed dimensions (length, width and thickness) and the hull thickness were obtained by measuring them for 100 of seeds using a sliding caliper. The proportions of the hull and kernel were obtained by measuring the corresponding masses on dehulling of $10 \mathrm{~g}$ of seeds. The moisture distribution was calculated based on the shares of the hull and kernel and of the corresponding moisture contents in them.
The moisture content in the seeds immediately before the beginning of wetting was $4.53 \%$ for the HOSS and $4.92 \%$ for the LSS sample. Sufficient amounts of both samples were prepared so that the approximate moisture contents were 6,8 and $10 \%$. The calculated amounts of water needed for achieving this were supplied with the aid of a laboratory sprayer. In order to achieve a uniform distribution of moisture, the seeds were thoroughly mixed and left in closed vessels for three days. After that, the moisture content in the HOSS sample was $6.11,7.98$ and $10.12 \%$, and in the LSS sample 6.05, 8.08 and $10.08 \%$. The moisture content was determined using 5-10 $\mathrm{g}$ of the sample dried 2 hours at $105 \pm 2{ }^{\circ} \mathrm{C}$, and the mass was measured after the sample cooling to room temperature (International Organization for Standardization, 2000). Of each sample, $250 \mathrm{~g}$ were placed into the injection block of the pneumatic air-jet impact dehuller, and the air of the pneumatic gun was set to 400,600 and $800 \mathrm{kPa}$. The dehuller cosnsits of an aluminum injection block, pneumatic gun, a skew positioned impact plate, cyclon, a receiver with conical ending, and a plexiglas container. After dehulling, the material at the dehuller outlet was collected quantitaively and manually separated into five fractions. The dehulled material was characterized by determining the percentages of the following fractions: whole kernels (A), broken kernels $\geq 3 \mathrm{~mm}$ (B), broken kernels $<2 \mathrm{~mm}$ and kernel powder $(\mathrm{F})$, hull $(\mathrm{H})$, and whole seeds $(\mathrm{U})$.

\subsection{Response surface methodology and statistical analysis}

Response surface methodology by Gupta et al. (2007) was used to determine the effect of seed moisture and dehulling pressure on the effectiveness of dehulling sunflower seeds prepared using different seed moisture content ( $\mathrm{w}, \mathrm{X}$-axis) and the air pressure of the dehuller ( $\mathrm{p}, \mathrm{Y}$-axis) as it is reported to be an effective tool for optimizing a process. A $3^{2}$ full factorial experimental design was employed to collect the data needed for the optimization of the dehulling process (Bezerra et al., 2008). The values of the coded and uncoded parameters are presented in Table 1. The dehulling effectiveness were evaluated as the dehulling efficiency (E criterion) and the quality of dehulling ( $\mathrm{K} 1$ criterion and $\mathrm{K} 2$ criterion). The dehulling efficiency was calculated as follows: $\mathrm{E}=\mathrm{H} \times \mathrm{r}$ ( $\mathrm{r}$ being the seed/hull ratio), $\mathrm{K} 1=\mathrm{F}+\mathrm{U}$, and $\mathrm{K} 2=\mathrm{A}+\mathrm{B}$. E, $\mathrm{K} 1$ and $\mathrm{K} 2$ criteria are dependent variables.

After their statistical treatment, the experimentally obtained values of the dependant variables were presented by the mathematical model in the form of a second-order polynomial equation of the general type (Bezerra et al., 2008; Equation 1):

$\mathrm{Z}=\mathrm{b}_{0}+\mathrm{b}_{1} \mathrm{X}+\mathrm{b}_{2} \mathrm{Y}+\mathrm{b}_{11} \mathrm{X}^{2}+\mathrm{b}_{22} \mathrm{Y}^{2}+\mathrm{b}_{12} \mathrm{XY}$

where $b_{0}, b_{1}, b_{2}, b_{12}, b_{11}$ and $b_{22}$ are the regression coefficients.

Table 1. Values of the coded levels of seed moisture and dehulling pressure.

\begin{tabular}{lccccccc}
\hline \multirow{2}{*}{ Independent variable } & \multicolumn{2}{c}{ Symbol } & & \multicolumn{3}{c}{ Level } \\
\cline { 2 - 3 } \cline { 5 - 7 } & Coded & Actual & & -1 & 0 & +1 \\
\hline Seed moisture, \% & $\mathrm{w}$ & $\mathrm{X}$ & & 6 & 8 & 10 \\
Dehulling pressure, $\mathrm{kPa}$ & $\mathrm{p}$ & $\mathrm{Y}$ & & 400 & 600 & 800 \\
\hline
\end{tabular}


If the partial derivatives of the second-order polynomial equation are set to zero, the following two equations are obtained (Bezerra et al., 2008; Equations 2 and 3):

$$
\frac{\partial Z}{\partial X}=b_{1}+2 b_{11} X+b_{12} Y=0
$$

$\frac{\partial \mathrm{Z}}{\partial \mathrm{Y}}=\mathrm{b}_{2}+2 \mathrm{~b}_{22} \mathrm{Y}+\mathrm{b}_{12} \mathrm{X}=0$

Statistical analysis of the experimental data was performed by the statistical packages MS Excel (Microsoft, 2010) and Statistica 13.0 (StatSoft Inc., 2013). Independent $t$-test was used to test the hypothesis about differences between two or more mean values $(p<0.05)$. All main coefficients such as linear, quadratic, and interaction, were calculated for each model. The regression coefficients were determined to assess the extent of the fitting to the polynomial as judged at a probability level of 0.05 . The response surface and contour plots for these models were plotted as a function of the two variables, the moisture content and dehulling pressure.

\section{Results and discussion}

\subsection{Composition of the fatty acids and technical and technological characteristics}

The composition of the fatty acids, as one of the basic qualitative characteristics of sunflower oil, shows that the seed of the HOSS genotype had a high content of oleic acid (C18:1) of $78.00 \pm 0.22 \%$ (Table 2). This is by about 3.5 times more compared to the content of the same acid in the seed of the LSS genotype, which was $23.15 \pm 0.12 \%$.

As can be seen from Table 2, there is an inverse correlation between the contents of oleic and linoleic acids, i.e. the higher the content of oleic acid, the lower the content of linoleic acid. Although the sums of unsaturated fatty acids (oleic and linoleic) are at a similar level with both sunflower genotypes (89-90\%), it should be pointed out that the contents of the dominant saturated fatty acids (palmitic and stearic) in LSS were lower. Namely, the mean values of the sum of palmitic and stearic acids in the HOSS sample was $6.86 \%$, compared to $9.68 \%$ in the LSS sample. The content of oleic acid in the HOSS sample was at the level of that in olive oil, so that it belongs to the group of oils containing about $80 \%$ of oleic acid (Fitch-Haumann, 1994).

Technical and technological characteristics of sunflower seeds are important from various aspects such as storing, processing, and especially of dehulling, as well as from the aspect of the oil quality and the economics of the production process. Table 2 presents the results of the determination of some basic technical and technological characteristics of the HOSS and LSS sample.

As it is evident from Table 2, the HOSS was characterized by a smaller size of seeds and had a smaller mass of 1000 seeds $(49.7 \pm 2.0 \mathrm{~g})$ compared to LSS $(55.2 \pm 2.2 \mathrm{~g})$. Besides, the proportion of the hull in the former sample was lower $(21.0 \pm 0.2 \%)$, and the hull was thinner $(0.19 \pm 0.05 \mathrm{~mm})$. Further, the distribution of the moisture in the hull and kernel is an essential indicator of
Table 2. Composition of the fatty acids in oil and some technical and technological characteristics of HOSS and LSS.

\begin{tabular}{lcc}
\hline \multicolumn{1}{c}{ Fatty acid, \%m/m of oil } & HOSS & \multicolumn{1}{c}{ LSS } \\
\hline C16:0 & $3.75 \pm 0.06^{\mathrm{a}}$ & $6.22 \pm 0.09^{\mathrm{b}}$ \\
C18:0 & $3.11 \pm 0.05^{\mathrm{a}}$ & $3.46 \pm 0.06^{\mathrm{b}}$ \\
C18:1 & $78.00 \pm 0.22^{\mathrm{a}}$ & $23.15 \pm 0.12^{\mathrm{b}}$ \\
C18:2 & $11.06 \pm 0.10^{\mathrm{a}}$ & $66.09 \pm 0.20^{\mathrm{b}}$ \\
C20:0 & $0.53 \pm 0.03^{\mathrm{a}}$ & $0.25 \pm 0.03^{\mathrm{b}}$ \\
C20:1 & $0.75 \pm 0.05^{\mathrm{a}}$ & $0.10 \pm 0.03^{\mathrm{b}}$ \\
C22:0 & $0.91 \pm 0.05^{\mathrm{a}}$ & $0.58 \pm 0.04^{\mathrm{b}}$ \\
C24:0 & $0.34 \pm 0.04^{\mathrm{a}}$ & $0.19 \pm 0.05^{\mathrm{b}}$ \\
Others & $0.88 \pm 0.05^{\mathrm{a}}$ & - \\
C16:0+C18:0 & $6.86^{\mathrm{a}}$ & $9.68^{\mathrm{b}}$ \\
C18:1+C18:2 & $89.06^{\mathrm{a}}$ & $89.24^{\mathrm{a}}$ \\
\hline \multicolumn{2}{c}{ Technical and technological characteristic }
\end{tabular}

\begin{tabular}{lll}
\hline \multicolumn{3}{c}{ Technical and technological characteristic } \\
\hline 1000 seeds weight, g (d.b.) & $49.7 \pm 2.0^{\mathrm{a}}$ & $55.2 \pm 2.2^{\mathrm{b}}$ \\
Bulk density, kg/dm ${ }^{3}$ & $0.45 \pm 0.01^{\mathrm{a}}$ & $0.43 \pm 0.01^{\mathrm{b}}$ \\
Actual density, kg/dm ${ }^{3}$ & $0.74 \pm 0.03^{\mathrm{a}}$ & $0.72 \pm 0.02^{\mathrm{a}}$ \\
Hull thickness, mm & $0.19 \pm 0.05^{\mathrm{a}}$ & $0.23 \pm 0.05^{\mathrm{b}}$ \\
Hull/kernel ratio, \% & $21.0 \pm 0.2^{\mathrm{a}}$ & $23.5 \pm 0.3^{\mathrm{b}}$ \\
Distribution of moisture, \% & $79.0 \pm 0.2^{\mathrm{a}}$ & $75.5 \pm 0.3^{\mathrm{b}}$ \\
- hull & & \\
- kernel & $37.0 \pm 0.2^{\mathrm{a}}$ & $38.0 \pm 0.3^{\mathrm{a}}$ \\
Seed/hull ratio (r), \% & $63.0 \pm 0.2^{\mathrm{a}}$ & $62.0 \pm 0.3^{\mathrm{a}}$ \\
\hline
\end{tabular}

The results are presented as the mean value \pm standard deviation $(\mathrm{n}=3)$. a,b Different lower-case superscripts represent significant differences between HOSS and LSS $(p<0.05)$. d.b.: dry basis.

the process of drying, storing, and seed dehulling. Although the moisture distribution in both HOSS and LSS was similar, it is evident that the difference in the hygroscopicity of the hull and kernel influences the structure and proportion of the hull. The seed size is of special importance for the process of dehulling and fractionation.

Figure 1 shows the distribution of the seed size in the most frequent spans of the seed thickness, width, and length. As can be seen, the thickness of more than $60 \%$ of HOSS was in the range of 2.5-3.5 mm, whereas the thickness of almost $80 \%$ of LSS was in the range of $2.0-2.5 \mathrm{~mm}$. On the other hand, the width of $80-90 \%$ of seeds of both types was in the range of 3.0-6.0 $\mathrm{mm}$, and the length in the range of $9.0-11.0 \mathrm{~mm}$.

\subsection{Dehulling effectiveness}

The obtained results are presented in the form of 3D graphs, showing the dependence of the effectiveness of the dehulling process expressed as the $\mathrm{E}$ criterion (Figures $2 \mathrm{a}$ and $2 \mathrm{~b}$ ), the $\mathrm{K} 1$ criterion (Figures $2 \mathrm{c}$ and $2 \mathrm{~d}$ ), and the $\mathrm{K} 2 \mathrm{criterion}$ (Figures $2 \mathrm{e}$ and $2 \mathrm{f}$ ), as a function of the moisture content and applied dehulling pressure for both HOSS and LSS type of sample.

As it can be seen, at the moisture content in the interval of 6-10\% and dehulling pressure ranging from 400 to $800 \mathrm{kPa}$, the E criterion is in the interval from $6.62 \pm 0.28 \%$ to $48.91 \pm 2.76 \%$ for HOSS and from $21.21 \pm 1.31 \%$ to $57.55 \pm 6.51 \%$ for LSS. Bearing in mind that the $\mathrm{E}$ criterion is a direct indicator of the dehulling efficiency, the aim is to maximize its value 


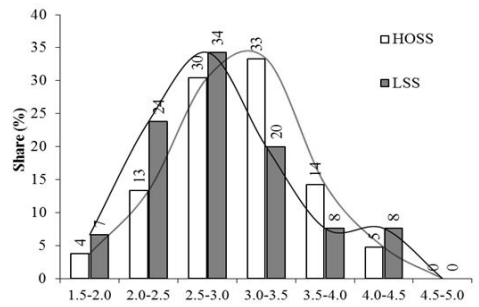

(a) Thickness (mm)

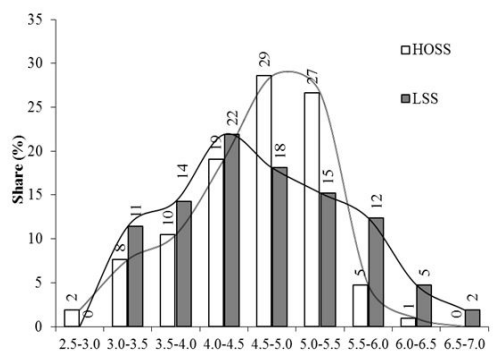

(b) Width (mm)

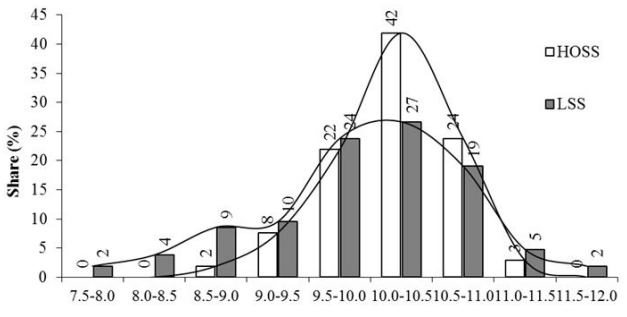

(c) Length (mm)

Figure 1. Distribution of the size of the seeds for HOSS and LSS: thickness (a), width (b), and length (c).

HOSS

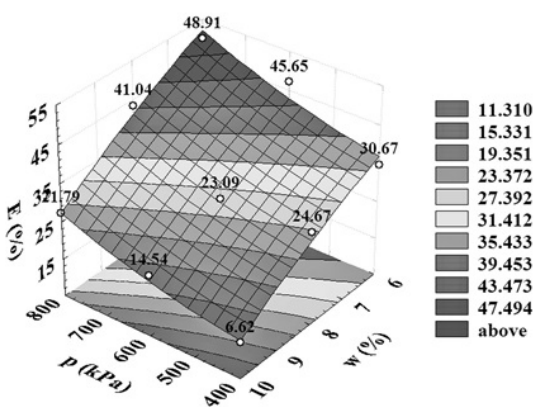

(a)

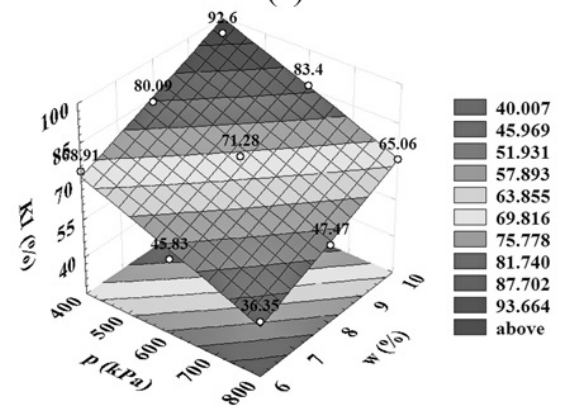

(c)

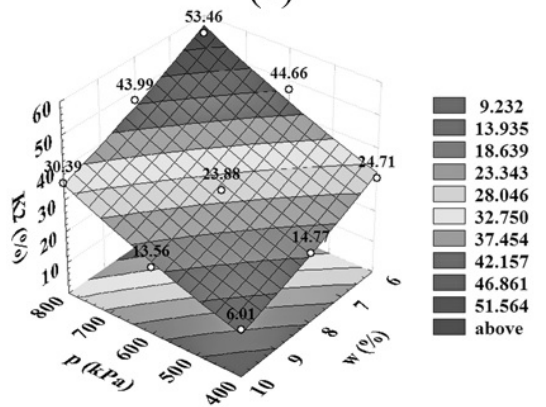

(e)
LSS

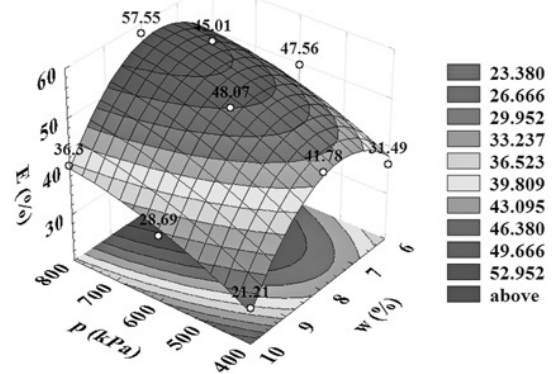

(b)

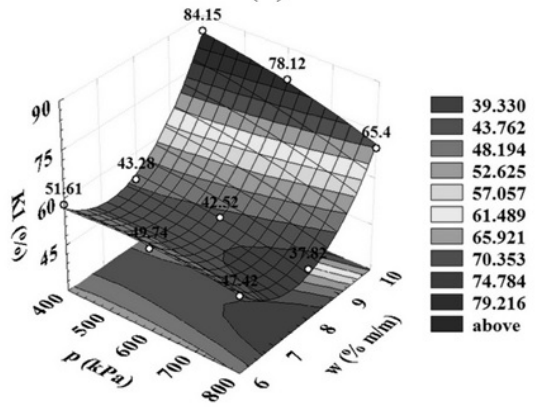

(d)

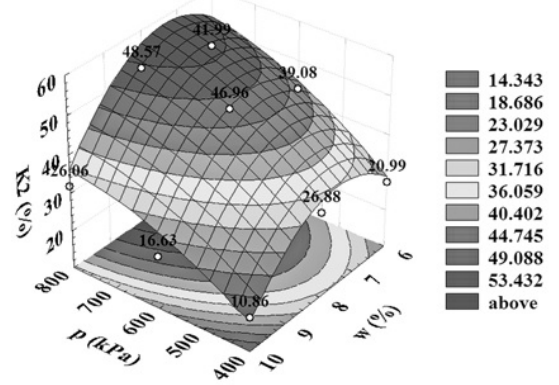

(f)

Figure 2. 3D graphics surface optimization for HOSS and LSS of the E criterion: (a) and (b), K1 criterion: (c) and (d) and K2 criterion: (e) and (f).

(E criterion $\rightarrow \max )$. A maximum efficiency of $57.55 \pm 6.51 \%$ for the LSS sample was obtained at the moisture content in the seed of $8 \%$ and air pressure of $800 \mathrm{kPa}$, whereas the efficiency in the case of the HOSS sample under the same conditions was statistically significantly $(p<0.05)$ lower $(41.04 \pm 5.28 \%)$. The most efficient dehulling of HOSS was achieved at the mositure content of $6 \%$ and air pressure of $800 \mathrm{kPa}$, and the value of the E criterion $(48.91 \pm 2.76 \%)$ was statistically significantly higher $(p<0.05)$ compared to that for LSS under the same conditions.
The dehulling efficiency of HOSS was significantly lower $(p<0.05)$ at the pressure of $800 \mathrm{kPa}$ and moisture content above $6 \%$, as well as at the pressure below $800 \mathrm{kPa}$ and unchanged moisture content (6\%). The efficiency of dehulling of LSS was significantly lower $(p<0.05)$ when, at the pressure of $800 \mathrm{kPa}$, the moisture content was either below $6 \%$ or above $10 \%$. Further, the E criterion for the LSS sample was significantly $(p<0.05)$ lower when, at the unchanged moisture content $(8 \%)$, the pressure was reduced below $800 \mathrm{kPa}$. Generally, it can be concluded 
that lower values of the moisture content and higher values of dehulling pressure yielded a statistically significant $(p<0.05)$ increase in the efficiency of dehulling of both types of seeds. Sharma et al. (2009), by investigating the dehulling of different high-oil sunflower hybrids using a centrifugal dehuller found that a maximum dehulling efficiency (ranging from 61.89 to $72.15 \%$ ) was obtained at the moisture content of $8.5 \%$.

It should be pointed out that the lowest efficiency of dehulling of both HOSS and LSS $(6.62 \pm 0.28 \%$ and $21.21 \pm 1.31 \%$, respectively) was obtained for the highest moisture content in the seed (10\%) and minimal air pressure (400 kPa). Under the given conditions, the efficiency of dehulling of HOSS was statistically significantly lower $(p<0.05)$ compared to LSS.

At the seed moisture in the range of 6-10\% and air pressure of 400-800 kPa the value of the K1 criterion was in the range of $36.35-92.60 \%$ for HOSS and of 37.82-84.15\% for LSS. Bearing in mind that the criterion $\mathrm{K} 1$ is an indirect indicator of the quality of dehulling and that the presence of the corresponding fraction is undesirable, the aim is to make its value as small as possible (K1 criterion $\rightarrow \mathrm{min}$ ). The lowest proportion of the undesirable $(\mathrm{F}+\mathrm{U})$ fraction $(\mathrm{K} 1$ criterion, $36.35 \pm 2.97 \%)$ for HOSS was obtained at the moisture content of $6 \%$ and air pressure of $800 \mathrm{kPa}$. Under the same dehulling conditions, the content of this fraction in LSS was statistically significantly higher $(p<0.05)$, amounting to $47.42 \pm 3.12 \%$. The lowest proportion of the $(\mathrm{F}+\mathrm{U})$ fraction for LSS $(37.82 \pm 2.33 \%$, ) was observed at the moisture content of $8 \%$ and air pressure of $400 \mathrm{kPa}$, which is statistically significantly lower $(p<0.05)$ compared to HOSS under the same working conditions. The share of the undesirable $(\mathrm{F}+\mathrm{U})$ fraction in the case of HOSS was significantly higher $(p<0.05)$ at the pressure of $800 \mathrm{kPa}$ and moisture content above $6 \%$. The same conclusion also holds for the air pressure lower than $800 \mathrm{kPa}$ and unchanged moisture content of $6 \%$. The quality of dehulling in the case of LSS decreased significantly $(p<0.05)$ when, at the unchanged pressure $(800 \mathrm{kPa})$, the moisture content was either decreased to $6 \%$ or increased to $10 \%$. In the case of LSS, the share of the undesired $(\mathrm{U}+\mathrm{F})$ fraction was statistically significantly higher $(p<0.05)$ when, at the unchanged moisture content of $8 \%$, the air pressure was decreased below $800 \mathrm{kPa}$. Further, the value of the K1 criterion increased significantly $(p<0.05)$, when, at the same pressure of $800 \mathrm{kPa}$ the moisture content was either $6 \%$ or $10 \%$. Based on the values of the $\mathrm{K} 1$ criterion, it can be concluded that lower values of the moisture content and higher values of the air pressure yielded a statistically significant increase $(p<0.05)$ in the quality of dehulling of both types of seeds.

At the seed moisture content in the range of 6-10\% and at the air pressure of $400-800 \mathrm{kPa}$ the share of the $(\mathrm{A}+\mathrm{B})$ fraction was in the range from $6.01 \pm 0.69 \%$ to $53.46 \pm 3.68 \%$, for HOSS, and from $10.86 \pm 1.31 \%$ to $48.57 \pm 4.74 \%$, for LSS. In view of the fact that the proportion of the $(\mathrm{A}+\mathrm{B})$ fraction is a direct indication of the quality of seed dehulling, the aim is to have this value as high as possible (K2 criterion $\rightarrow \max )$. The highest proportion of the $(\mathrm{A}+\mathrm{B})$ fraction of $53.46 \pm 3.68 \%$ was obtained for the seed moisture content of $6 \%$ and the dehullinh pressure of $800 \mathrm{kPa}$ for HOSS, and $41.99 \pm 3.30 \%$ for LSS under the same conditions, which is a statistically significant difference $(p<0.05)$. The highest proportion of the $(\mathrm{A}+\mathrm{B})$ fraction of $48.57 \pm 4.74 \%$, in the case of LSS was obtained ar the moisture content of $8 \%$ and the air pressure of $800 \mathrm{kPa}$, which was significantly higher $(p<0.05)$ compared to HOSS under the same conditions. The proportion of the $(A+B)$ fraction for HOSS was significantly lower $(p<0.05)$ when, at the same pressure of $800 \mathrm{kPa}$, the moisture content was above $6 \%$, as well as when the pressure was below $800 \mathrm{kPa}$ at the moisture content of $6 \%$. The share of the $(A+B)$ fraction for LSS was statistically significantly lower $(p<0.05)$ when, at the same pressure of $800 \mathrm{kPa}$, the moisture content was either decreased to $6 \%$ or increased to $10 \%$. Also, this value ( $\mathrm{K} 2$ criterion) was significantly lower $(p<0.05)$ when, at the moisture content of $8 \%$, the air pressure was below $800 \mathrm{kPa}$. In this case too, on observing the values of the $\mathrm{K} 2$ criterion, it can be concluded that lower moisture contents and higher air pressures yielded a significant enhancement in the quality of dehulling of both types of sunflower seeds.

The obtained data are presented in Table 3.

\subsection{Optimization the process of dehulling}

It has been demonstrated that the regression equations derived on the basis of experimental results by applying response surface methodology (Figure 2), can be used as mathematical models to calculate effectively $\left(R^{2}>0.90\right)$ the values of the dependent variables (the criteria $\mathrm{E}, \mathrm{K} 1$ and $\mathrm{K} 2$ ), i.e. for the determination of the optimum conditions for the dehulling of HOSS and LSS and the experimental values were found to be in high agreement with the predicted ones (Table 4).

The process of dehulling is of special importance in the sunflower processing since the presence of hull leads to a significant deterioration of the oil quality (Dimić et al., 1999). This fact is even more important in the production of cold-pressed oil, where no additional treatment or refining is involved (Dimić, 2005). According to Šmit et al. (2005), the cold-pressed oil obtained from the dehulled sunflower seeds is of a much higher quality and has a longer shelf life compared to the oil produced from the whole seeds.

The results obtained in this study confirmed the already known fact that the dehulling of high-oil sunflower hybrids is a rather probematic process (Tranchino et al., 1984). This is mainly due to the morphological characteristics of the seed, with a very thin hull firmly adhering to the kernel, and its proportion in the seed is small. Karlović et al. (1992) found that the most effective dehulling of the Olivko sunflower was achieved at the moisture content in the seed of $5 \%$ and the dehulling pressure of $620 \mathrm{kPa}$. A comparison of the results obtained in the dehulling of HOSS with those obtained for confectionary sunflower shows a drastic difference (Karlović et al., 1992; Pajin et al., 2011). Namely, the dehulling efficiency in the latter case was much higher, ranging from 60.00 to $79.00 \%$. This is a consequence of the fact that the hull of the confectionary sunflower is thicker $(0.24-0.28 \mathrm{~mm})$ and its proportion in the seed is higher (about 30\%). With the seeds of both HOSS and LSS, the hull thickness was in the range from $0.19 \pm 0.05$ to $0.23 \pm 0.05 \mathrm{~mm}$, and the proportion of the hull in the seed was in the range from $21.0 \pm 0.2 \%$ to $23.5 \pm 0.3 \%$ (Table 2 ). 
Table 3. Estimated coefficients of the fitted second-order polynomial equation for different responses.

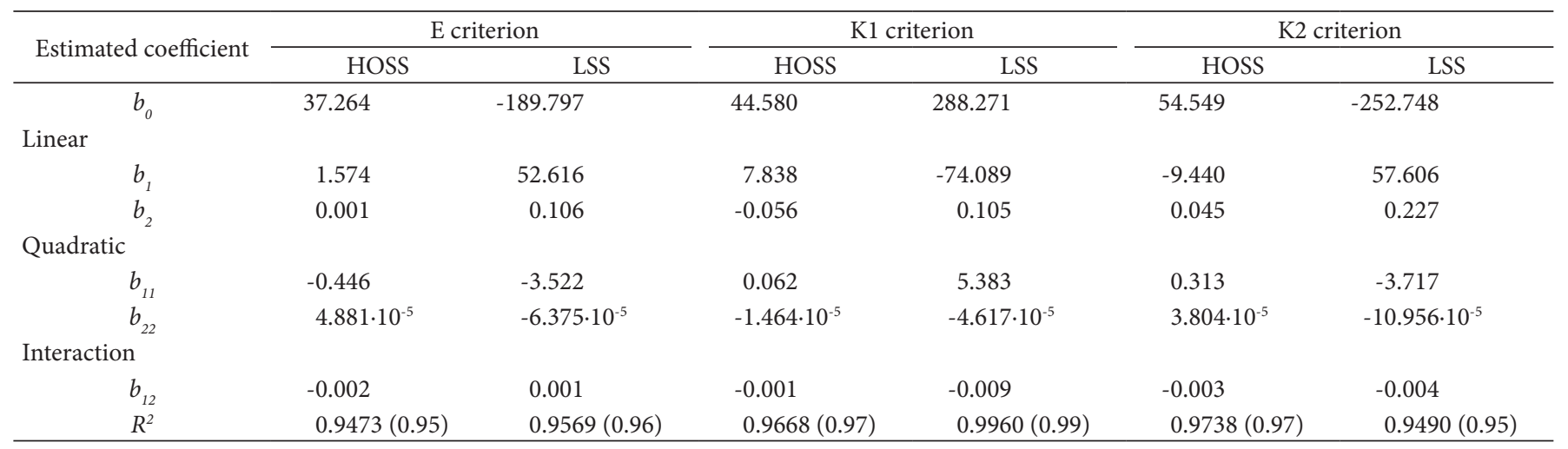

Table 4. Correlation between the experimental and calculated values and comparison of the calculated (predicted) and experimental conditions.

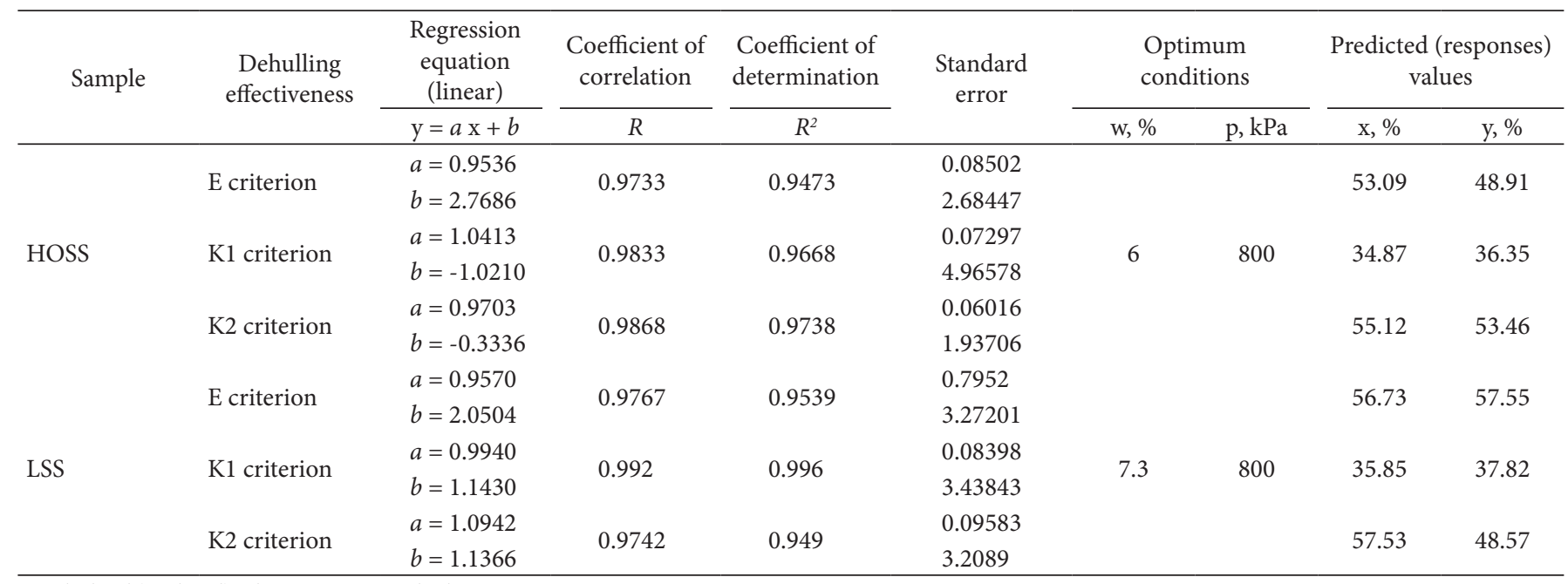

$\mathrm{x}$ : calculated (predicted) value; $\mathrm{y}$ : experimental value; $p<0.0001$.

\section{Conclusion}

Although the dehulling of sunflower seeds was a very problematic operation, no essential difference in the efficiency of the process were found in respect of the seed type. Of much greater importance were the differences in respect of the seed moisture content and applied air pressure. However, significant differences were observed in the quality of dehulling, especially in the new criterion K2. Namely, under the optimized conditions for HOSS (moisture content of $6.0 \%$ and air pressure of $800 \mathrm{kPa}$ ), the $\mathrm{K} 2$ criterion (referring to the content of the desirable fraction), was $53.46 \%$ (predicted value was $55.12 \%$ ), whereas for LSS it was $41.99 \%$. On the other hand, the minimal value of the K1 criterion (undesired fraction) under the optimum conditions for HOSS was $36.35 \%$ (predicted value was $34.87 \%$ ), and for LSS $47.42 \%$. The optimized conditions for LSS were moisture content of $7.6 \%$ and air pressure of $800 \mathrm{kPa}$. Finally, it has been demonstrated that the regression equations derived on the basis of the experimental results by applying response surface methodology can serve as the mathematical models that allow one to calculate effectively $\left(\mathrm{R}^{2}>0.90\right)$ the values of the dependent variables (the criteria $\mathrm{E}, \mathrm{K} 1$ and $\mathrm{K} 2$ ), i.e. to determine the optimum conditions for dehulling of HOSS and LSS.

\section{Acknowledgement}

This research is financed by Ministry of Education, Science and Technology Development of the Republic of Serbia, Project Number 451-03-68/2020-14/200134.

\section{References}

Bajaj, M., Kaur, A., \& Sidhu, J. S. (1991). Studies on the development of nutritious cookies utilizing sunflower kernels and wheat germ. Plant Foods for Human Nutrition, 41(4), 381-387. http://dx.doi. org/10.1007/BF02310631. PMid:1665564.

Bezerra, M. A., Santelli, R. E., Oliveira, E. P., Villar, L. S., \& Escaleira, L. A. (2008). Response surface methodology (RSM) as a tool for optimization in analytical chemistry. Talanta, 76(5), 965-977. http:// dx.doi.org/10.1016/j.talanta.2008.05.019. PMid:18761143.

Dimić, E. (2005). Cold pressed oils (Monograph). Faculty of Technology, University of Novi Sad, Novi Sad, Serbia.

Dimić, E., Romanić, R., Jovanović, D., \& Pajin, B. (2006). Quality of row and thermal treated kernel of proteic sunflowerseed. In Proceedings (II) of IV International Eco-Conference: Safe Food. Novi Sad, Serbia and Montenegro: Ecological Movement of Novi Sad Serbia. 
Dimić, E., Turkulov, J., \& Pap, J. (1999). Nutritive value enhancing of edible nonrefined sunflower oil. In Proceedings of 7 th Symposium: Vitamins and Additives in the Nutrition of Man and Animal. Jena/ Thüringen, Germany.

Dozet, B., \& Vuković, Z. (2007). Perspectives of the high oleic sunflower in Serbia. In Proceedings of 48th Conference: Production and Processing of Oilseeds. Herceg Novi, Montenegro.

Figueiredo, A. K., Baumler, E., Riccobene, I. C., \& Nolasco, S. M. (2011). Moisture-dependent engineering properties of sunflower seeds with different structural characteristics. Journal of Food Engineering, 102(1), 58-65. http://dx.doi.org/10.1016/j.jfoodeng.2010.08.003.

Fitch-Haumann, B. (1994). Modified oil may be key to sunflowers future. Inform, 5, 1198-1210.

Garcés, R., Martínez-Force, E., Salas, J. J., \& Venegas-Calerón, M. (2009). Current advances in sunflower oil and its applications. Lipid Technology, 21(4), 79-82. http://dx.doi.org/10.1002/lite.200900016.

Grompone, M. A. (2020). Sunflower and high-oleic sunflower oils. In F. Shahidi (Ed.), Bailey's industrial oil and fat products (7th ed.). New Jersey: John Wiley \& Sons. http://dx.doi.org/10.1002/047167849X. bio017.pub2.

Gupta, R. K., Sharma, A., \& Sharma, R. (2007). Instrumental texture profile analysis (TPA) of shelled sunflower seed caramel snack using response surface methodology. Food Science \& Technology International, 13(6), 455-460. http://dx.doi.org/10.1177/1082013207088369.

International Organization for Standardization - ISO. (2000). ISO method 665: oilseeds: determination of moisture and volatile matter content (2nd ed.). Geneva: ISO.

Karlović, Đ., \& Andrić, N. (1996). Quality control of oil seeds. Belgrade: University of Novi Sad, Faculty of Technology, Novi Sad and Federal Bureau of Standards.

Karlović, Đ., Dimić, E., Turkulov, J., \& Škorić, D. (1992). Dehulling efficiency of sunflower hybrids Gricko, Olivko and NS-H-45 with the laboratory „air-jet” impact dehuller. In Proceedings of the 13th International Sunflower Conference (Vol. II). Pisa, Italy.

Lima, I. M., \& Guraya, H. S. (2005). Optimization analysis of sunflower butter. Journal of Food Science, 70(6), s365-s370. http://dx.doi. org/10.1111/j.1365-2621.2005.tb11457.x.

Microsoft. (2010). Microsoft Excel: computer software. Washington. Retrieved from www.microsoft.com
Miklič, V., Hladni, N., Jocić, S., Marinković, R., Atlagić, J., SaftićPanković, D., Miladinović, D., Dušanić, N., \& Gvozdenović, S. (2008). Sunflower breeding at Institute of field and vegetable crops. Proceedings of Institute of Field and Vegetable Crops, 45(1), 31-63.

Munder, S., Argyropoulos, D., \& Müller, J. (2017). Class-based physical properties of air-classified sunflower seeds and kernels. Biosystems Engineering, 164, 124-134. http://dx.doi.org/10.1016/j. biosystemseng.2017.10.005.

Pajin, B., Dimić, E., Romanić, R., \& Radujko, I. (2011). Influence of fatty acid composition of sunflower kernel on quality and shelf-life of cookies. Acta Aliment Hun, 40(1), 71-79. http://dx.doi.org/10.1556/AAlim.40.2011.1.10.

Przybylski, R., \& Michael Eskin, N. A. (2006). Minor components and the stability of vegetable oils. Inform, 17, 187-189.

Raß, M., Schein, C., \& Matthäus, B. (2008). Virgin sunflower oil. European Journal of Lipid Science and Technology, 110(7), 618-624. http://dx.doi.org/10.1002/ejlt.200800049.

Sharma, R., Sogi, D. S., \& Saxena, D. C. (2009). Dehulling performance and textural characteristics of unshelled and shelled sunflower (Helianthus annuus L.) seeds. Journal of Food Engineering, 92(1), 1-7. http://dx.doi.org/10.1016/j.jfoodeng.2008.10.013.

Škorić, D., Demurin, J., Jocić, S., Lečić, N., \& Verešbaranji, I. (1994). Production of sunflower hybrids for different oil quality. In Proceedings of the Conference on Yugoslavia Improving Oil Production. Bar, Yugoslavia.

Šmit, K., Dimić, E., Romanić, R., Bjelobaba-Bošnjak, K., \& Mojsin, B. (2005). Influence of hull on cold pressed sunflower oil quality. In Proceedings of 46th Conference: Production and Processing of Oilseeds. Petrovac na moru, Serbia and Montenegro.

Sosulski, F. (1979). Food uses of sunflower proteins. Journal of the American Oil Chemists' Society, 56(3), 438-442. http://dx.doi. org/10.1007/BF02671532. PMid:536561.

StatSoft Inc. (2013). Statistica: data analysis software system, v.13.0. Tulsa. Retrieved from www.statsoft.com

Tranchino, L., Melle, F., \& Sodini, G. (1984). Almost complete dehulling of high oil sunflower seed. Journal of the American Oil Chemists' Society, 61(7), 1261-1265. http://dx.doi.org/10.1007/BF02636267.

Vasić, N. (2006). Protein sunflower for confectionery industry (B. Sci. Thesis). Faculty of Technology Novi Sad, University of Novi Sad, Serbia.

Wittkop, B., Snowdon, R. J., \& Friedt, W. (2009). Status and perspectives of breeding for enhanced yield and quality of oilseed crops for Europe. Euphytica, 170(1-2), 131-140. http://dx.doi.org/10.1007/s10681-009-9940-5. 